\title{
Design of an Evacuation Demand Forecasting Module for Hurricane Planning Applications
}

\author{
Gary P. Moynihan1, Daniel J. Fonseca² \\ ${ }^{1}$ Department of Civil, Construction, and Environmental Engineering, The University of Alabama, Tuscaloosa, AL, USA \\ ${ }^{2}$ Department of Mechanical Engineering, The University of Alabama, Tuscaloosa, AL, USA \\ Email: gmoynihan@eng.ua.edu, dfonseca@eng.ua.edu
}

How to cite this paper: Moynihan, G.P. and Fonseca, D.J. (2016) Design of an Evacuation Demand Forecasting Module for Hurricane Planning Applications. Journal of Transportation Technologies, 6, 257-276. http://dx.doi.org/10.4236/jtts.2016.65024

Received: July 27, 2016

Accepted: September 24, 2016

Published: September 27, 2016

Copyright $\odot 2016$ by authors and Scientific Research Publishing Inc. This work is licensed under the Creative Commons Attribution International License (CC BY 4.0).

http://creativecommons.org/licenses/by/4.0/

\begin{abstract}
This paper discusses the development and implementation of an evacuation demand forecasting module that was incorporated into a comprehensive decision support system for the planning and management of contraflow operations in the Gulf of Mexico. Contraflow implies the reversing of one direction of a highway in order to permit a substantially increased travel demand exiting away from an area impacted by a natural disaster or any other type of catastrophic event. Correctly estimating the evacuation demand originated from such a catastrophic event is critical to a successful contraflow implementation. One problem faced by transportation officials is the arranging of the different stages of this complex traffic procedure. Both the prompt deployment of resources and personnel as well as the duration of the actual contraflow affect the overall effectiveness, safety and cost of the evacuation event. During this project, researchers from the University of Alabama developed an integral decision support system for contraflow evacuation planning to assist the Alabama Department of Transportation Maintenance Bureau in the evaluation and planning of contraflow operations oriented to mitigate the evacuation burdens of a hurricane event. This paper focuses on the design of the demand forecasting module of such a decision support system.
\end{abstract}

\section{Keywords}

Hurricane Evacuation, Road Capacity, Demand Forecasting, Decision Support System

\section{Introduction}

An increasing number of Alabama's population lives in the eight counties close to the Gulf of Mexico [1], thus making them vulnerable to tropical storms, hurricanes and other extreme weather events. The normal response to these occurrences is to evacuate 
inland from the coast. Normal traffic flows turn into congestion, frustration and gridlock. This reduces the number of vehicles that can leave the Gulf area if an evacuation order is given. The potential risk for catastrophic loss increases if the hurricane strikes stalled traffic, and necessitates further evacuation planning. Such hurricane evacuation planning led to the State of Alabama's initial plan to "reverse-lane" I-65 to expedite such evacuations from the Gulf Coast. "Reverse-laning", or "contraflow", is the process of reversing one direction of traffic on specific routes to facilitate overall evacuation flow. This procedure is generally applicable to Interstates, referred to as "denied access routes", since traffic control can be applied to interchanges and terminal areas.

\subsection{Current System Review}

Alabama and several other neighboring states have adopted the concept of contraflow in hurricane evacuation. The idea is to reverse one direction of the roadway in order to accommodate the often substantially increased travel demand moving away from the impact area. The actual contraflow implementation mechanism varies from state to state. One of the more elaborate contraflow procedures is the one that Mississippi and Louisiana share. Mississippi does not utilize contraflow if the only impact area is the coastal area of that state, since the existing roadways can adequately handle evacuation traffic without any modifications. However, an evacuation from New Orleans, Louisiana would bring a large amount of additional traffic to Mississippi. Therefore, the two states have established a coordinated hurricane evacuation plan. In this plan, the state of Louisiana will initiate contraflow operation within their borders, and coordinate with Mississippi to extend such operation if needed. The contraflow plan of Louisiana will be implemented 30 hours before the winds from a hurricane of Category 3 and above are anticipated to hit land along the Louisiana coast. Contraflow operations will then be activated when evacuations are initiated in Jefferson and Orleans parishes [2]. If the state of Louisiana decides to implement contraflow within the borders of Louisiana only, their Department of Transportation will contact the Mississippi Department of Transportation (MDOT) for their assistance, giving MDOT at least three hours to mobilize the people and equipment necessary to terminate the contraflow operations at the state line. Should it be necessary for the contraflow to extend into Mississippi, the Louisiana governor will contact the Mississippi governor to request initiating contraflow within Mississippi along I-55 and I-59 at least four hours before the desired activation time [3].

In Texas, the orders to evacuate come from the mayor or county judge [4], and each local area follows its own contraflow plan. The contraflow plans for each urban area are detailed on the Texas Department of Transportation website [5]. In general, actual contraflow operations will not begin in Texas unless official evacuation orders are issued. For voluntary evacuations, Texas has an "evacuation" plan for some specified roadways [5]. Under this plan, if voluntary evacuation orders are given, there is no actual lane reversal, but the shoulders of the road are used as travel lanes. Similarly, each county in Florida has its own hurricane evacuation plan, with contraflow options along 
the following roadways: I-75, I-10, I-4, the Florida Turnpike, and SR 528 [6].

In Alabama, an approximately 140-mile section of I-65 between exit 31 and exit 167 is identified as the contraflow segment. In this case, I-65 would be reverse-laned such that all traffic would flow north, from south of Alabama Route 225, near Mobile, to Exit $167 / 168$, just south of the greater Montgomery metropolitan area [7]. On the ALDOT website, a detailed contraflow (also called reverse-laning) plan is available [8]. The plan specifies four contraflow operating levels. Level 1 begins with the start of hurricane season where necessary assets and personnel assignments are reviewed and equipment and materials are provided to each predetermined staging location. Level 2 begins with the National Weather Service issuing a hurricane watch for the gulf coasts of Alabama and Mississippi or the Florida panhandle. Assigned personnel will be contacted and equipment and materials will be loaded in this stage. Level 3 begins when the watch is upgraded to a warning where personnel and equipment are to be moved into their assigned locations. Level 4 begins with the Transportation Director for the state of Alabama calling the contraflow into effect based on the advice of Alabama Emergency Management Association (AEMA), and extends to when the Transportation Director issues the order to end contraflow and return to normal traffic operations. Contraflow operations in Alabama involve the cooperation of three Alabama agencies: ALDOT, Alabama Department of Public Safety (ADPS), and AEMA. ALDOT develops the necessary plans and infrastructure to handle contraflow; ADPS enforces contraflow operations for the duration of Level 4; and AEMA counsels the other agencies on emergency management practices. As noted in Figure 1 [7], this concept was further refined after Hurricane Katrina, to provide emergency vehicles with an alternate route south via U.S. 31.

Although the contraflow operation increases roadway capacity for evacuation, it is by nature an unusual measure. Practical implementation issues range from traffic control, access management, and use of roadside facilities to safety, labor requirements, and cost [9]. Therefore, care must be taken in the planning and real-time operations of contraflow evacuation.

\subsection{Deficiencies of the Current Approach}

Evacuation demand is an important input in determining the onset and duration of contraflow operation. In practice, however, it is difficult to estimate this demand. In addition to the total evacuation demand, the temporal and spatial distributions of such demand are also essential to contraflow planning. Temporal distribution has to do with when people in the impacted areas decide to begin their evacuation. The temporal distribution can be described by a demand profile consisting of estimated evacuation demand for each time interval. The spatial distribution is a result of evacuees' choices of various feeder routes to access the contraflow facility.

In view of the safety, cost and other related issues, one critical decision is when to start contraflow and how long it should last. Such decisions are often made in an ad hoc manner in actual implementation. The current practice in Alabama is a staged process. 


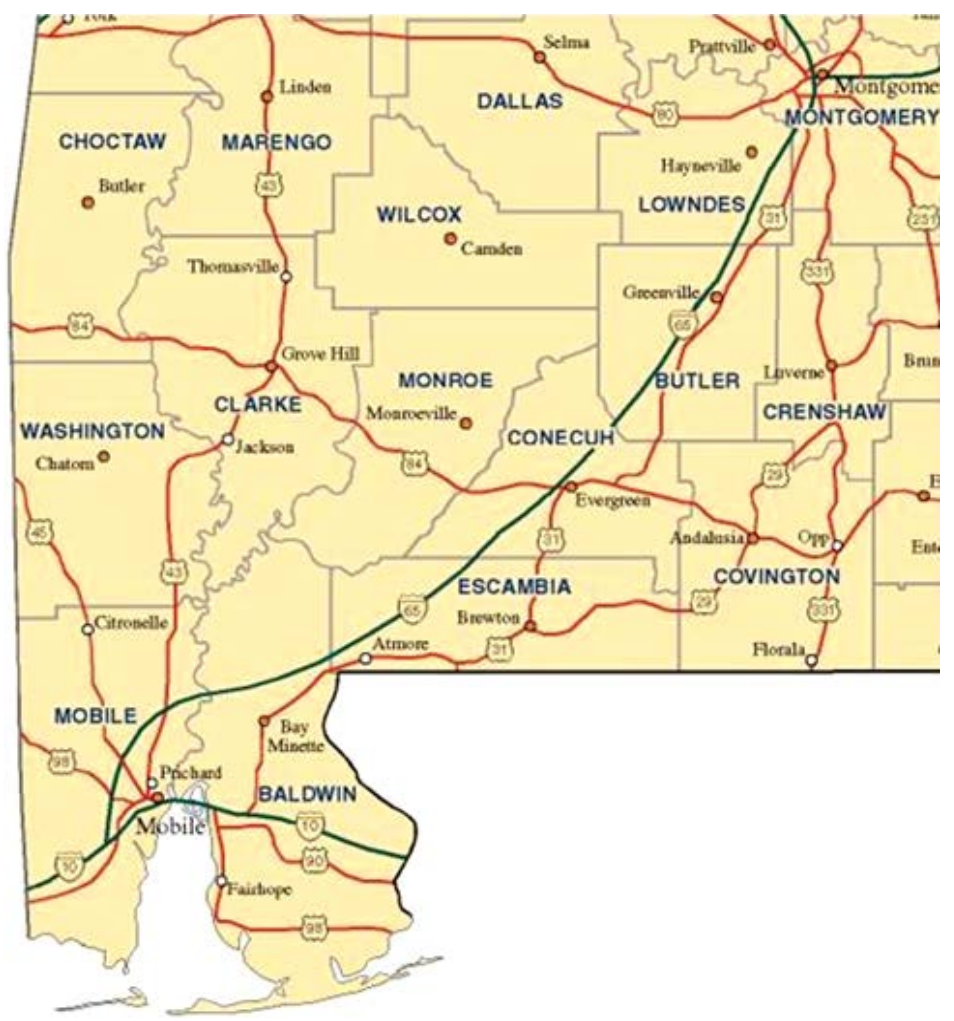

Figure 1. Map of contraflow evacuation in Alabama.

Equipment and personnel are deployed first, and the actual call for reversing the southbound lanes depends on the measured traffic condition and other relevant factors [7].

A final problem faced by Alabama Department of Transportation is the scheduling of different phases in the staged process. The timing for the deployment of equipment and personnel, as well as the initiation and termination of actual contraflow, affects the effectiveness, safety and cost of the operation. The contraflow scheduling problem is characterized by both uncertainties with unknown probability distribution and staged decision process. The three decision stages are timing for equipment and personnel deployment at first, initiation of contraflow, and termination of the operation. At the early stage, information on uncertain traffic and weather conditions is very limited, and all three decisions need to be considered in an integrated manner to assess the overall effect for a particular timing plan for deploying the equipment.

This research investigated various methodologies and developed a design for a computer-based tool to help the decision making in contraflow scheduling. The proposed system will have the ability to explicitly optimize the contraflow onset and duration based on the existing and forecasted traffic and weather conditions. Factors such as neighboring states' evacuation status and mandatory evacuation order will also be considered. Resulting from these efforts is the system design depicted in this paper.

\section{Project Objective and Approach}

A further advancement is proposed to better meet the needs of state traffic planners. 
Decision support systems (DSS) are software systems that use advanced algorithmic approaches to solve problems. Within the DSS, the data processor (i.e. the database management system) controls the access and update of data from both internal and external files and datasources. The modelbase contains the specific analytical methods used for processing the accessed data. Such methods normally invoke the use of specific algorithms for the particular type of mathematical model under consideration [10].

Accepted DSS development methodology frequently identifies four primary phases: 1) data acquisition, 2) system design, 3) system construction, and 4) verification and validation (e.g. [10]). The first two phases were addressed by this research project. An initial iteration of the third and fourth phases is represented via the development of a spreadsheet prototype, as discussed in this paper. During the data acquisition phase, the key concepts, relationships and sources were identified. ALDOT databases were investigated to obtain relevant data on interstate and state highways in the vicinity of the I-65 contraflow segment. The availability of this relevant data was explored. Traffic data collected included annual average daily traffic, turning movements at exit and entry ramps, percentage of heavy vehicles, average travel speed etc., for both normal traffic conditions and during evacuation conditions from archived historical data. Road geometrics data such as number of lanes, location of on and off ramps, interchanges, median crossovers etc., were gathered. Information on the populations of evacuating counties, as well as their corresponding persons-vehicle ratios, was obtained. Finally the data related to incidents during evacuation, including number of occurrences, type of incidents, location, response time, clearance time, queue buildup, etc., were collected from historical databases.

Methods resulting from subsequent project tasks determined the candidate models for incorporation into this systemic framework. Many conventional algorithmic models may not sufficiently apply to specific problem areas, e.g. traffic planning. The utilization of computer-based simulation, within a DSS, is a long-accepted means of modeling complex systems and their behavior. A simulation model is largely mathematical in nature. Rather than directly describing the overall behavior of the system under investigation, the simulation model attempts to "replicate" this behavior by studying the interrelations among its components. The system is decomposed into elements whose behavior can be predicted in terms of probability distributions, for each of the various possible states of the system and its inputs [11]. Model output is normally presented in terms of selected measures that reflect the performance of a system.

Simulation has many advantages. It may provide a complete view of the total operational flow. Perhaps the most important advantage of simulation is that it provides the opportunity for "what-if" analysis. It can project the impact of factors under a variety of conditions. The various decision alternatives then may be evaluated economically, without disrupting existing operations, or incurring unnecessary costs.

A modular system design approach was devised as noted in Figure 2, and consists of three interrelated components: the demand forecasting module; the network simulation (optimization) module; and the incident detection and characterization module. The 


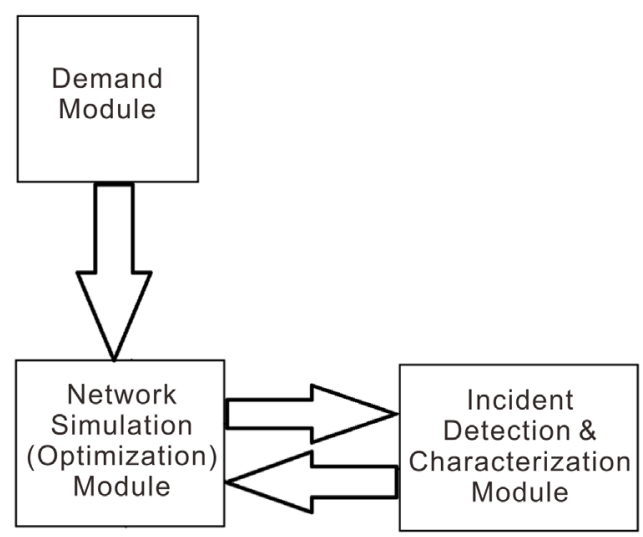

Figure 2. Summary DSS architecture.

focus of this paper addresses the development of the demand forecasting module within this systemic context. Discussion of the functionality and processing of the other modules is provided by Fonseca et al. [12] and Lou et al. [13].

\section{Methodology}

The study site was examined in detail. The initial crossover from the northbound to the southbound lanes is located at milepost (MP) 30.3. The crossover consists of two lanes, and is 0.03 miles long. The I-65 contraflow section terminates at Exit 167, just south to the greater Montgomery metropolitan area. The final crossover is located at MP (milepost) 167.3. Similarly, the 0.03-mile crossover has two lanes. The immediate downstream segment of the north terminus is a four-lane freeway, which becomes a threelane facility at Exit 168. In order to account for the impact of the merging traffic on the entire contraflow operation, the study site was extended to MP 170. It was noted that the merging only occurs on northbound lanes, and the southbound lanes do not carry traffic beyond the north terminus. Therefore, the study site in this project consisted of a 140-mile section of I-65 northbound lanes starting from MP 30 and ending at MP 170, and a 138-mile section of I-65 southbound lanes between MP 30 and MP 168. Relevant geometry and traffic information of the study site was obtained from the ALDOT roadway inventory database, as well as Google Maps. Available variables included number of lanes, lane widths, location of exit ramps, lengths of acceleration and deceleration lanes, and posted speed limits.

Subsequently, a comprehensive literature search was conducted. The purpose of this literature search was to identify and understand current theory regarding hurricane evacuation demand forecasting, and the subsequent contraflow planning that could be initiated from this. Work was performed to demonstrate the feasibility of using the available traffic measurements and travel time data provided by the Alabama Department of Transportation to develop an automated system. The references identified can be broadly divided into empirical studies of specific hurricane case studies and articles discussing specific algorithmic models. A few of the articles bridge both categories. It is important to note that many of the algorithmic model references provide an even more 
extensive literature review (e.g. [14]).

Although the focus was the identification and evaluation of candidate evacuation demand models for incorporation into this research project, investigation identified a large number of literature articles devoted to individual and collected hurricane evacuation case studies. These included the Alabama Hurricane Evacuation Study [15] [16], the Federal Highway Administration's Best Practices for Road Weather Management [17], the Georgia Department of Transportation Hurricane Preparedness and Response [18], and the National Oceanic and Atmospheric Administration's Hurricane Planning and Evacuation Assessment Reports [19]. These references emphasize best practices and lessons learned from a number of hurricane evacuations, as opposed to identifying specific algorithmic models to forecast demand. They did prove valuable as sources of data that could support the later selected models. Both the "Alabama Hurricane Evacuation Study-Summary Report" [15] and the related "Alabama Hurricane Evacuation Study-Transportation Study" [16] were particularly useful.

A number of algorithmic techniques have been developed to support the evacuation traffic planning and analysis process. These may be broadly categorized as deterministic versus probabilistic in nature. A separate group of references were observed to rely on the use of specific application software to forecast evacuation demand.

As noted by Fonseca et al. [6], "massive terrestrial evacuations can be seen as a network optimization problem aiming at selecting optimal routes from a set of candidate roads within an existing evacuation network". These network representations of evacuation problems are extensions of the classical operations research assignment problem. For these problems, the basic form of the network is that of the more general minimal cost transshipment (or flow) network. In the network, the arcs represent the flow of people, the source nodes represent initial source inventories (points of entrance into the evacuation network), and the sink nodes represent the final inventories (in this case, destinations). Optimization models (e.g. linear programming, goal programming or dynamic programming) are another category of mathematical models. The model is formulated to either maximize (or minimize) the objective function (depending upon the purpose of the model) within the context of available resources and constraints. A survey of classical examples of transportation network optimization modeling is provided by LeBlanc [20], Magnanti and Wong [21], Yang and Bell [22], and Solanski et al. [23].

Within the list of articles surveyed, Lindell and Prater [14] provide a set of simple, deterministic equations, with supporting empirical data, to model evacuation demand. Tanaka [24] presents a deterministic traffic model, consisting of a suite of integrated equations, noting an irregular set of traffic "waves" during an evacuation situation. Burger's equation (which is provided within this article) is specified to describe how the vehicle density varies with time. Abdelgawad and Abdulhai [25] describe a very largescale optimization model utilizing multiple transportation modes (e.g. personal vehicles, mass transit). Within this model, a demand estimation equation is provided to quantify the evacuation demand for the various transportation modes. The model is 
then applied to a proposed evacuation situation for the City of Toronto.

Probabilistic models analyze natural conditional variants, as opposed to establishing a single mathematical optimum. For example, Wilmot and Mei [26] applied regression to investigate evacuation demand probabilities and behavior in Southwest Louisiana during Hurricane Andrew. Similarly, Fu and Wilmot [27] incorporated a logit model to estimate the conditional probability of households evacuating during a specific time period prior to hurricane landfall.

As noted earlier in this paper, computer simulation is a preferred means of modeling such probabilistic representations. Different levels of traffic representations are used by different classes of simulation models. In microscopic simulation models, the interactions of individual vehicles "are captured by using algorithms that represent vehicle acceleration and deceleration, passing maneuvers, and lane changing behavior" [28]. Tanaka [29] provides a similar microscopic simulation model of hurricane evacuation on a single lane highway. The amount of detail, that is required at the microscopic level, becomes overwhelming when trying to model a large-scale evacuation over an extensive area. Macroscopic or mesoscopic models are preferred under such circumstances. Macroscopic models are used to simulate traffic flow based on speed and traffic density relationships, and do not model the detailed interactions between individual vehicles. Mesoscopic simulation models seek a compromise approach. They address individual vehicles in the transportation system, but capture their relationships using aggregate relationships.

A number of articles in the literature describe the application of specific software packages to evacuation modeling, including demand estimation. These software applications may utilize either deterministic or probabilistic approaches. However, the underlying mathematical models may not be clearly indicated. For example, Nasser and Birst [28] describe a case study for the modeling the evacuation of a small city using DYNA-SMART software. DYNA-SMART employs mathematical programming with a traffic simulator to produce traffic flow projections.

Two software-specific references were identified that dealt explicitly with the problem of contraflow for evacuation. Chen [30] utilized the Census Transportation Planning Package (CTPP), Version 2000, to estimate the evacuation demand for Washington D.C. Contraflow was applied to some of the routes exiting the city. Pal et al. [31] applied the Oak Ridge Evacuation Modeling System (OREMS), in concert with the ArcView geographical information system (GIS) software package, to evaluate traffic conditions resulting from evacuation from Baldwin and Mobile counties in Alabama. OREMS is a probabilistic traffic simulation tool. It consists of a pre-processor for data input, a simulation model, and a post-processor that is linked to the GIS for the results output and simulation. This approach is further detailed by Pal [32].

Regarding contraflow specific research, the I- 65 evacuation route has been subject to considerable analysis (e.g. [3] [33]). Fonseca et al. [9] developed an overall proof of concept simulation model, initially focusing on management of entry ramps, applied to selected areas of the I-65 extended network. The study involved eight counties and 
twenty entry ramps along I-65. These data were obtained with the help of the Alabama Department of Transportation, and the Alabama Demographics Center. In the primary model, entering vehicles are created through a controlled wait-and-signal mechanism. Attributes such as time of arrival, final destination exit, and accident incident proneness are established at this level. These attributes are assigned based on cumulative probability distributions generated by empirical data collected during the data acquisition phase of the project. Additionally, a maximum batch number of entering vehicles at each entry ramp was set based on the total amount people residing in the communities close to the corresponding ramp, and the pre-established evacuation ratio. This evacuation ratio is an estimate of the fraction of the population exiting from a particular area as determined by ALDOT officials.

\section{Design of the Demand Module}

Selection of a suitable evacuation demand model was requisite to support the needs of the Alabama Department of Transportation Maintenance Bureau regarding contraflow pre-planning and evaluating possible responses to a hurricane event. Beyond the adequacy of the demand model itself, the necessary supporting data must also be available. As noted by Nasser and Birst [28], "a limitation in evacuation models is that they are focused on developing new traffic flow models while few of them considered the background data and behavior aspects analysis. Ignoring the human behavior aspects when modeling emergency evacuation could lead to underestimating ETEs" (evacuation time estimates)." Distinct advantages of the simple deterministic models portrayed by Lindell and Prater [14] are that the authors identify the principal behavioral variables affecting hurricane ETEs, and describe the available empirical data relevant to evacuation demand modeling. Further analysis noted that observed data in the Alabama Hurricane Evacuation Study [15] mapped well to the Lindell and Prater approach, and could be used to better finetune it to the needs of the Alabama DOT. A flow diagram of the resulting module design is provided in Figure 3.

\subsection{Input Specifications}

Upon initiation of the demand module, the user will be prompted to enter data regarding the planning date, the category of hurricane, the cumulative traffic count on I-65 since the evacuation notice, and the anticipated number of vehicles merging on to I-65 from I-10. As noted earlier in this paper, computer simulation is a preferred means of modeling such probabilistic representations from ALDOT or other personnel on site. The default value for these fields will be 0 . These data would be merged with system internal files denoting current population of the area, population by evacuation zone, and percentage of households expecting to evacuate to generate the residential evacuation demand, consistent with the Lindell and Prater [14] algorithms. These files would be developed in Excel. Similarly, Excel-based data files denoting quantity of hotel rooms and occupancy rates would forecast the transient evacuation demand. These two demand streams would be combined to create the overall traffic demand profile. 


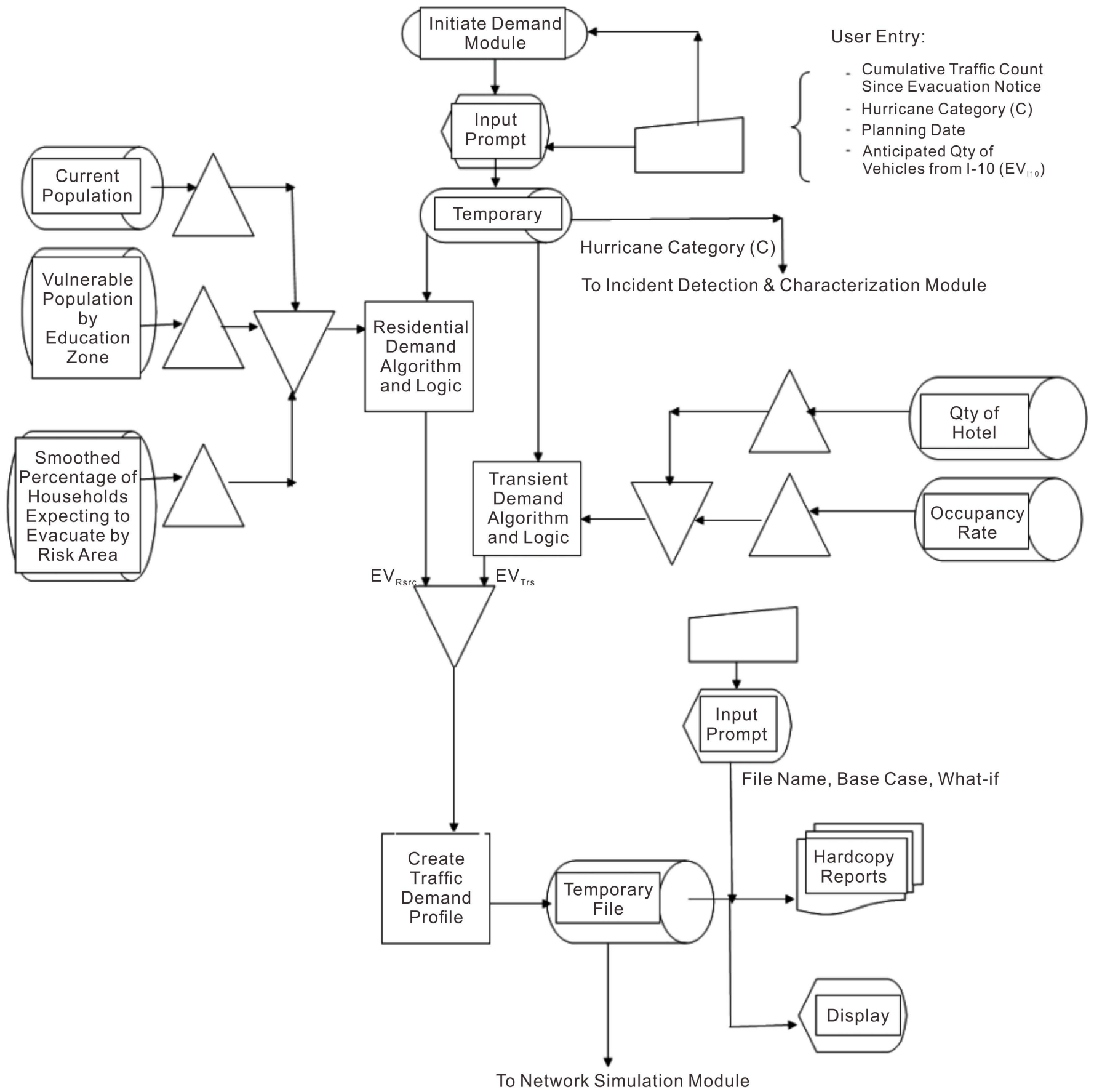

Figure 3. Evacuation demand module flow diagram.

Population data for each of these counties can be accessed from a table [16], which links to individual evacuation risk area. This table was based on Year 2000 population figures. Within the demand module, the number of households must be adjusted for DRrc, the proportion of residential households in Risk Area $r$ deciding to evacuate in Hurricane Category c. This data was obtained from [14].

Residents of the area comprise one component of the evacuation population. Tran- 
sient population (e.g. tourists and "beach-goers") are also a sizeable consideration for evacuation during hurricane season. There are approximately 10,000 hotel rooms in the Mobile Bay area (i.e. Mobile and Baldwin Counties). Other input data, to support the calculation of transient population impact on the evacuation demand, is provided by monthly occupancy hotel occupancy rates was generated by researchers at the University of South Alabama [34], and is the most recent year that this data was compiled. The system will use the 68.43 percent occupancy rate for the peak summer months that correspond with hurricane season.

\subsection{Processing Specifications}

The processing details of the underlying algorithmic models, with their associated calculations, are discussed in this section. Processing with the Evacuation Demand Module follows the approach discussed in detail by [14].

$$
\text { Total Demand }=\text { EVRsrc }+ \text { EVTrs }+ \text { EVI-10 }
$$

where:

EVRsrc is the number of residential vehicles evacuating from Sector s of Risk Area $r$ during Hurricane Category c, and EVTrs is the corresponding number of evacuating vehicles for transients. EVI-10 is the anticipated number of vehicles expected to merge onto I-65 from I-10 (I-10 is a major interstate route along the northern Gulf Coast, and could bring significant levels of additional traffic from either New Orleans to the west or the Florida panhandle to the east).

In these variables, subscript $\mathrm{R}$ denotes residential vehicles, and subscript $\mathrm{T}$ denotes vehicles for transients (e.g. occupants of hotels, condominiums, and rental houses in beach areas). Hurricane Category $c$ is determined from weather reports at the time of analysis, and can be entered via the initial Demand Module Input Screen. Sector s is specific population center within Risk Area $r$.

As noted by Lindell and Prater [14], EVRrsc then can be estimated by:

$$
\text { EVRrsc }=(\text { PopRrsc } / \text { PHHR }) \text { DRrc }(1-T D R)(\text { EVHHR }+ \text { ETHHR })(1-S r) \text { URrs }
$$

where:

PopRrs = residential population of Sector $s$ in Risk Area $r$ and PHHR $=$ number of persons per residential household, both of which can be estimated from 2010 census data. The household is the critical unit in evacuation, so demand should be based on this unit of analysis (the first term in parentheses). For Mobile County: PopRrs $=412,992$ and PHHR $=2.55$, and for Baldwin County: PopRrs $=182,265$ and PHHR $=2.49$. To account for 2010 population figures, for each category of evacuation zone:

Evacuation Factor

$$
=\frac{(2000 \text { Portion of Mobile }+ \text { Non-Mobile Home Population Evacuating })}{(2000 \text { Mobile Home }+ \text { Non-Mobile Home Populations })}
$$

and

Revised Non-Mobile \& Mobile Home Population

$=2010$ County Residential Population * Evacuation Factor 
The number of households must be adjusted for DRrc, the proportion of residential households in Risk Area $r$ deciding to evacuate in Hurricane Category c (i.e., compliance and spontaneous evacuation). EVHHR, the average number of vehicles taken by each household during evacuation, and ETHHR, the number of trailers taken by each residential household, to generate the number of evacuating vehicles from residential households. For EVHHR, use "the number of vehicles per evacuating household ranged from 1.16 to 1.36", as noted in the Behavioral Studies section in U.S. Army Corp of Engineers [15]. For ETHHR, the same study noted "few evacuees pulled trailers or took motor homes. In Bay County, 7.5 percent took such vehicles, and in Okaloosa/Walton, only 2.5 percent did so. A five percent rate is the lowest which should be used for planning" [16]. According to Lindell and Prater [18], analysts should also adjust for the number of evacuating households downward for the proportion of transit dependent residential households, TDR, but recognize that census data will overestimate the number who will need to be evacuated by bus. In the Alabama Hurricane Evacuation Study Behavioral Studies section [15], TDR would translate to 6 percent and was generally provided by relatives and families. Further, this behavioral study indicated, "One other factor is also clear: very few evacuees (less than 20 percent) leave before officials issue an evacuation notice." It was noted that for Hurricane Opal, this value was found to be 10 percent. This value can be used for Sr in the equation for EVRrsc.

Lindell et al. [35] found that the residents' expectations of using designated evacuation routes ranged from a low of 9 percent to a high of 37 percent. All of these uncertainties underscore the need to conduct sensitivity analyses to produce plausible error bounds around point estimates of ETEs. Per subsequent discussion with research team members, the underlying model has been modified to provide the total number of evacuating vehicles/day. The original model considered the variable " $U$ " to relate to the use of the designated evacuation route (here I-65). It thus constrains the output number of evacuating vehicles. In order to better coordinate functionality with the downstream network simulation module, $\mathrm{U}$ would initially equal 1.0 in the model, thus yielding the total number of evacuating vehicles from the area. This will allow the network simulation module to conduct the subsequent routing to I-65.

Again, as noted by Lindell and Prater [14], the corresponding estimate of the number of evacuating vehicles for transients (EVTrs) should be computed by:

$$
\text { EVTrs }=\operatorname{HRrsOR}(1-\mathrm{Sr}) \mathrm{UT} \text {. }
$$

HRrs equals the number of hotel rooms (and campsites) in Sector s of Risk Area r, and OR equals the aggregate occupancy rate for these facilities, both of which can be determined from Mobile Bay area convention/visitors bureau records. There are approximately 10,000 hotel rooms in the Mobile Bay area (i.e. Mobile and Baldwin Counties). A table of monthly occupancy hotel occupancy rates was generated by researchers at the University of South Alabama [34], and is the most recent year that this data was compiled. Based on this data, it is recommended to use a default value of 68.43 percent occupancy rate for the peak summer months that correspond with hurricane season. Lindell and Prater [14] further note that "there are no available data on ST, the propor- 
tion of early evacuees among the transients, or UT, the proportion of transients who use the primary evacuation routes.

However, ST is almost certain to be higher than SR because transients have fewer reasons to remain in the risk area when a storm approaches. UT is likely to be very close to 1.0 because transients are likely to know very little about unofficial evacuation routes. Of course, if ST is high (most transients leave early), the value of UT will make little difference in the ETEs." EVI-10 would be obtained either as a value in what-if analysis for planning purposes, or as an observed value of traffic on I-10 in the event of an actual hurricane, and entered via the module input screen noted in Figure 3 flow diagram.

\subsection{Use of the Model to Create a Traffic Demand Profile}

During the period prior to the hurricane's landfall, ALDOT personnel will need to create a traffic demand profile to assist in their planning responsibilities. The level of demand will change as progressively more people evacuate from their respective zones. The initial concept to address this issue is to modify SR. Prior to the official evacuation notice. SR $=10$ percent based on the previously referenced Alabama Hurricane Evacuation Study by the Army Corps of Engineers [16]. After the official evacuation notice is issued:

\section{Revised SR}

$=.10+[$ Cumulative Traffic Count Since Evacuation Notice/Total Expected $]$

where:

$.10=$ Portion of early evacuees in decimal form and Cumulative Traffic Count since Evacuation Notice is based on ALDOT observation or traffic recorder data.

$$
\begin{aligned}
\text { Total Expected }= & (2010 \text { PopRS } / \mathrm{PHH}) \mathrm{DRrC}(1-\mathrm{TDR}) \\
& \times(\mathrm{EVHH}+\mathrm{ETHH}) \mathrm{URrs}+(\mathrm{HRrs} \times \mathrm{OR} \times \mathrm{UT})
\end{aligned} .
$$

Total Expected evacuation traffic includes components for both residents and transients. The transient ST factor is conservatively assumed to be equal to SR in this case. The demand model employing the revised SR factor is expected to be updated on a daily basis to create the traffic profile for each day up to hurricane landfall.

\subsection{Further Refinements}

Subsequent discussion with ALDOT indicated that a hurricane landfall to the east of Alabama would have considerable impact on the evacuation traffic using I-65, while a landfall to the west does not have a significant effect. In view of this, $E V_{I_{-10}}$ from the west is no longer considered in the model. A further investigation of the road network use, in Alabama and Florida, revealed that multiple routes exist for evacuees from the Florida panhandle to access I-65, besides I-10. In fact, for most of the Florida panhandle counties, I-10 is not the best route to access I-65. For example, AL-113 could be a shorter route for residents from northern Escambia County and Santa Rosa County in Florida. Evacuees from Okaloosa and Walton counties could head straight north and 
get onto I-65 through AL-106, rather than going all the way west along I-10 and then travel northeast along I-65. ALDOT experience confirmed that Exit 69 (AL-113) and Exit 114 (AL-106) are two major interchanges to experience high traffic arrival rates during past hurricane evacuation events. Therefore, it was determined that evacuation demand from the Florida panhandle (when hurricane landfall is to the east of Alabama) should be treated in a similar manner as evacuation demand from Alabama.

A demand profile describes the cumulative percentage of departed evacuating population as a function of time. The initial equations, however, did not adequately describe when the remaining evacuation demand would depart. A range of cumulative departure curves have been proposed in the literature (e.g. [14]) to model evacuation departure time distribution. Upon further analysis, the Rayleigh distribution (Equation (8)) was adopted as the base demand loading profile. This is because the shape of the distribution function is a desired sigmoid curve; the function is easier to calibrate as it only has one parameter $\beta$; and various studies have adopted this distribution and calibrated it against empirical data [14].

$$
p_{t}=1-\exp \left[-0.5(t / \beta)^{2}\right]
$$

Note that the reference time in this base model is the issue time of an official evacuation order [14]. It is also worth noting that the base model does not consider night-time evacuation behavior, and is appropriate only for day-time evacuation. However, it has been observed from historical hurricane events that the evacuation demand during the night is usually low, even in the case of large, intense storms [15]. Based on empirical data of evacuation response rates during Hurricane Opal in 1995 [36], this study assumes that the average evacuation rate is 2 percent per hour during nighttime (12AM $5 \mathrm{AM})$. Based on this assumption, the base evacuation demand profile will be adjusted according to the issue time of the official evacuation order.

\section{Development of the Spreadsheet Prototype}

The goal of this project is to assist ALDOT in the planning of contraflow operations for hurricane evacuation along I-65. Within this broad goal, one of the specific objectives is to determine conditions that warrant the initiation of a contraflow operation, and the best onset and duration of such operation when it is necessary. With the methodologies described in Section 4, a prototype Excel spreadsheet was developed as an initial proofof-concept implementation of the Demand Module design. It was utilized to analyze the capability of the module design to address various contraflow operation alternatives under a range of testing scenarios. Data needed for demand estimation are stored in six Excel worksheets, representing the six counties considered. One worksheet is designated for user inputs. Since the Demand Module consists of three sets of models for estimating the total evacuation demand, the demand profile (temporal distribution of the demand), and the traffic distribution among multiple feeder routes to the study site (spatial distribution of the demand), the program outputs are respectively displayed in three separate worksheets. 


\subsection{Impact Areas Considered}

While all of the Alabama counties south of Montgomery have hurricane mitigation plans, this study will only focus on Mobile and Baldwin, the two coastal counties of Alabama. Four Florida panhandle counties are also considered based on ALDOT's previous experiences that a hurricane landfall to the east of Alabama will lead to a limited demand increase for I-65. The four Florida counties considered are: Escambia, Santa Rosa, Okaloosa, and Walton. Evacuation zones are established for each of the six counties by the emergency management agency in their respective state. The zones are generally a relatively large area including multiple cities, small towns, and rural districts. The zones for Mobile and Baldwin counties are established by Alabama Emergency Management Agency [37], and indicated in Table 1. Detailed maps of these zones may be viewed at the website provided by the Mobile Emergency Management Agency [38]. The evacuation zones established by the Florida Emergency Management Agency are based on coastal storm surge levels [39].

Before Equation (4) could be utilized to generate a demand profile, the parameter $\beta$ needed to be calibrated. Historical traffic counts at MP42 on I-65 during past hurricanes were available from ALDOT, and used for this calibration. Some of the hurricanes, represented in the ALDOT database, are of low intensity (e.g. Tropical Storm Arlene, Hurricane Dennis, Hurricane Gustav, and Hurricane Ike), and some have landfall locations far away from Alabama (e.g. Katrina). Due to these reasons, those hurricanes events are not ideal candidates for calibration. Their data were eliminated from the calibration test set. Hurricane Ivan landed just west of Gulf Shores, Alabama as Category 3 hurricane, which made it the best candidate for calibration use. The official evacuation order was issued at 9:00 am on September 14. The hurricane category and official evacuation time provide inputs to the demand models. A simulation program, developed by this research team, was developed to calibrate the parameter of interest. The simulation was able to output hourly traffic counts at any milepost within the study site. The calibration was conducted by comparing the simulation outputs with the real traffic counts at MP42 [40].

Since URrs is also unknown, various combinations of URrs and $\beta$ were tested. Values of other parameters and inputs of the demand models were set as described in the previous subsection. The mean squared error (MSE) was adopted as the performance measure for calibration. In other words, a set of URrs and $\beta$ with the smallest MSE is

Table 1. Evacuation zone locations.

\begin{tabular}{cc}
\hline Zone \# & Location \\
\hline I & South of Interstate 10 \\
II & North of Interstate 10; East of Interstate 65; and East of US 43 \\
III & North of Interstate 10; South of US 98; and West of Interstate 65 \\
IV & North of US 98; West of Interstate 65; and West of US 43 \\
\hline
\end{tabular}


considered the best calibrated results. After extensive calibration efforts, it was determined that aURrs of 15 percent and a $\beta$ of 400 are the best calibrated values for Hurricane Ivan. This was interpreted as the majority of residents, being familiar with the local roadways, actually utilized informal routes as opposed to the designated I-65. With this set of values, the simulated traffic condition at MP42 is comparable to real traffic data. It also validates that the recommended demand loading profile is suitable for a real hurricane evacuation event. Since parameter $\beta$ governs the shape of the demand loading curve and is independent from the total demand (controlled by hurricane category and URrs), the value of 400 will be used for $\beta$ in the formal development of the Network Simulation Module.

It is assumed that all evacuees from the same Census tract (the traffic analysis unit in this study) will use the same route to access I-65. The travel time from a tract to a particular exit of I-65 is calculated using the distance from the center of the tract to the exit and the free flow speed on the major feeder routes. Most major feeder routes only lead to one I-65 exit. Approaching evacuation traffic was be assigned to the route with the shortest instantaneous travel time.

\subsection{Demand Scenarios}

Total evacuation demand for I-65 is adjusted by varying hurricane category, percentage of the total evacuation demand using I-65 (URrs in Equation (2)), and location of landfall (whether I-65 will receive evacuation demand from Florida or not). During model calibration against real traffic data from Hurricane Ivan, a hurricane of Category 3 with a landfall in Alabama, it was determined URrs of 15 percent leads to the best calibration result. The simulation results indicate that the traffic is not particularly heavy under this scenario, and contraflow operation is not necessary as the study site is not very congested. Therefore, all the testing scenarios generated are of Category 3 and above. Similarly, 15 percent was chosen as the starting value of URrs for each hurricane category. Four values of URrs (15, 20, 25, and 30 percent) were used to generate demand scenarios. This was based on observation during pre-testing that a 5 percent increment leads to a desirable demand increase. In addition, pre-testing also revealed that aURrs of more than 30 percent will result in severe network-wide congestion that lasts for more than two days even with contraflow operating at all times. With three hurricane categories (Category 3 - Category 5), four values of URrs, and two possible landfall locations (in AL or in FL), twenty-four demand scenarios were generated. Table 2 provides sample output with consideration of Florida demand.

An abbreviated file name was created for each testing scenario. The abbreviation follows the convention $C_{-} M_{-} U_{-}[\mathrm{FL}]$. "C" stands for hurricane category, "M" for time of an official evacuation notice, $U$ for parameter URrs, and finally an optional suffix "FL" indicates whether evacuation demand from Florida is present or not. For example, C3M9U015 represents a scenario where a Category 3 hurricane makes a landfall in Alabama; the official evacuation notice is issued at 09:00; and 15 percent of the total evacuation demand will use I-65. In this scenario, the total demand is from Baldwin 
Table 2. Sample demand levels generated.

\begin{tabular}{ccccc}
\hline & \multicolumn{3}{c}{ URrs } \\
\cline { 2 - 5 } & 0.15 & 0.20 & 0.25 & 0.30 \\
\hline Category 3 & 62,591 & 83,456 & 104,322 & 125,185 \\
Category 4 & 71,347 & 95,130 & 118,915 & 142,698 \\
Category 5 & 73,851 & 98,469 & 123,086 & 147,705 \\
\hline
\end{tabular}

and Mobile counties only. The suffix of FL indicates the demand from Florida is included. Take C3M9U015FL for instance, demand from Escambia, Okaloosa, Santa Rosa, and Walton counties is loaded in addition to demand from the two Alabama counties.

\section{Conclusions}

For this research project, the University of Alabama (UA) researchers developed an algorithmic methodology to be utilized for hurricane evacuation demand forecasting by the Alabama Department of Transportation during contraflow planning. Analysis of available data helped determine the specific model needed. The algorithmic methodology, initially developed by Lindell and Prater [14] was modified and adapted to the available data obtained from the U.S. Army Corps of Engineers studies [15] [16] [36].

The resulting Demand Module consists of three sets of models for estimating the total evacuation demand, the demand profile (temporal distribution of the demand), and the traffic distribution among multiple feeder routes to the I-65 contraflow section (spatial distribution of the demand), respectively. Relevant data were collected from the Census database and reasonable assumptions were made. The models were calibrated against traffic data collected during Hurricane Ivan in 2004. The Demand Module is able to generate various demand scenarios, to account for low departure rate during night, and to incorporate considerations of feeder route choices [13].

Extensive analysis was then performed to determine conditions that warrant a contraflow operation, and the best onset and duration of such operation when it is necessary. The analysis was performed using a prototype spreadsheet tool that implements the modeling framework developed in this project. With each setting, two baseline contraflow schedules (i.e. no contraflow and full-time contraflow) were simulated initially. If the difference between the two schedules is higher than a pre-specified threshold (15 percent in this study), multiple contraflow scheduling solutions will further analyzed according to an evaluation logic and a near-optimal scheduling solution will be identified. Otherwise, contraflow is deemed not necessary. Alternative contraflow strategies and the impact of incidents are further investigated through paired comparison.

The methodology is being incorporated into a more extensive computer-based module, which will be the first of a three-module decision support system. The system will consist of the following primary components: a Demand Module (as discussed in this 
paper), an Incident Generation and Characterization Module, and a Network Simulation Module. The design of the other modules is currently underway. Their subsequent programming, integration and test will be conducted during a planned follow-on project. This initiative will provide ALDOT traffic officials with relevant insights and expertise to forecast, detect and characterize traffic situations that may drastically impair evacuation responses during a potential natural disaster.

\section{References}

[1] Gerdes, B. (2007) 16 Percent of Alabamians Live in Hurricane Counties, According to UA's State Data Center, NOAA. The University of Alabama News. http://uanews.ua.edu/anews2007/jun07/counties061307.htm

[2] Louisiana Governor's Office of Homeland Security \& Emergency Preparedness (2011) Official Louisiana Hurricane Survival Guide.

[3] Mississippi Department of Transportation (2012) Contraflow Plan for Interstate Hurricane Evacuation Traffic Control.

http://sp.mdot.ms.gov/Enforcement/Emergency\%20Services/Emergency\%20Preparedness/ Contraflow/Contraflow\%20Plan.pdf

[4] Government of the State of Texas (2012) Evacuating to Safety. http://emergency.portal.texas.gov/en/Pages/Evacuating-to-Safety.aspx

[5] Texas Department of Transportation (2012) Hurricane Evacuation Contraflow Publications. http://www.dot.state.tx.us/travel/contraflow_publications.htm

[6] Fonseca, D.J., Moynihan, G.P., Johnston, J. and Jennings, J. (2010) A Simulation Tool for Hurricane Evacuation Planning. Modelling and Simulation in Engineering, 2009, Article ID: 729570 .

[7] Alabama Department of Transportation (2010) I-65 Contra-Flow Plan: 2010 Hurricane Season. http://ema.alabama.gov/GSHC\%20-ALDOT\%20Contraflow\%20201

[8] Alabama Department of Transportation (2008) Plan for Reverse-Laning Interstate I-65 in Alabama for Hurrican Evacuation. http://www.dot.state.al.us/maweb/reverse_laning

[9] Wolshon, B. (2001) "One-Way-Out": Contraflow Freeway Operation for Hurricane Evacuation. Natural Hazards Review, 2, 105-112. http://dx.doi.org/10.1061/(ASCE)1527-6988(2001)2:3(105)

[10] Turban, E. and Aronson, J. (2001) Decision Support Systems and Intelligent Systems. Prentice Hall, Upper Saddle River.

[11] Hillier, F. and Lieberman, G. (2004) Introduction to Operations Research. 8th Edition, McGraw-Hill, New York.

[12] Fonseca, D.J., Lou, Y., Moynihan, G.P. and Gurupackiam, S. (2013) Incident Occurrence Modeling during Hurricane Evacuation Events: The Case of Alabama's I-65 Corridor. Modelling and Simulation in Engineering, 2013, Article ID: 168126. http://dx.doi.org/10.1155/2013/168126

[13] Lou, Y., Li, P., Fonseca, D.J., Moynihan, G.P. and Gurupackiam, S. (2014) Scheduling of Contraflow Evacuation: A Case Study of I-65 in Alabama. Journal of Transportation Engineering, Manuscript Currently under Review.

[14] Lindell, M.K. and Prater, C.S. (2007) Critical Behavioral Assumptions in Evacuation Time Estimate Analyses for Private Vehicles: Examples from Hurricane Research and Planning. Journal of Urban Planning and Development, 133, 18-29. 
http://dx.doi.org/10.1061/(ASCE)0733-9488(2007)133:1(18)

[15] US Army Corps of Engineers (2001) Alabama Hurricane Evacuation Study-Summary Report. http://chps.sam.usace.army.mil/USHESdata/Alabama/ALmainreport.htm

[16] US Army Corps of Engineers (2001) Alabama Hurricane Evacuation Study-Transportation Study. http://chps.sam.usace.army.mil/USHESDATA/Alabama/altranspage.htm

[17] Federal Highway Administration (2003) Best Practices for Road Weather Management. http://ops.fhwa.dot.gov/weather/best_practices/CaseStudiesFINALv2-RPT.pdf

[18] Georgia Department of Transportation (2005) Georgia DOT Hurricane Preparedness and Response 2005. http://www.itsga.org/Knowledgebase/GA\%20hurrevac\%2007282005.pdf

[19] National Oceanic and Atmospheric Administration (2011) Hurricane Planning and Evacuation Assessment Reports. http://www.csc.noaa.gov/hes/hes.html

[20] LeBlanc, I.J. (1975) An Algorithm for the Discrete Network Design Problem. Transportation Science, 9, 183-199. http://dx.doi.org/10.1287/trsc.9.3.183

[21] Magnanti, T.L. and Wong, R.T. (1984) Network Designs and Transportation Planning: Models and Algorithms. Transportation Science, 18, 1-55.

http://dx.doi.org/10.1287/trsc.18.1.1

[22] Yang, H. and Bell, M.G.H. (1998) Models and Algorithms for Road Network Design: A Review and Some New Developments. Transportation Reviews, 18, 257-278. http://dx.doi.org/10.1080/01441649808717016

[23] Solanski, R.S., Gorti, J.K. and Southworth, F. (1998) Using Decomposition in Large-Scale Highway Network Design with a Quasi-Optimization Heuristic. Transportation Research Part B, 33, 127-140. http://dx.doi.org/10.1016/S0191-2615(97)00020-9

[24] Tanaka, K. (2007) Traffic Mixing in Deterministic Two-Lane Model of Hurricane Evacuation. Physica A: Statistical Mechanics and Its Applications, 380, 490-502. http://dx.doi.org/10.1016/j.physa.2007.02.068

[25] Abdelgawad, H. and Abdulhai, B. (2010) Managing Large-Scale Multimodal Emergency Evacuations. Journal of Transportation Safety \& Security, 2, 122-151. http://dx.doi.org/10.1080/19439962.2010.487636

[26] Wilmot, C. and Mei, B. (2004) Comparison of Alternative Trip Generation Models for Hurricane Evacuation. Natural Hazards Review, 5, 170-178. http://dx.doi.org/10.1061/(ASCE)1527-6988(2004)5:4(170)

[27] Fu, H. and Wilmot, C. (2004) A Sequential Logit Dynamic Travel Demand Model. Proceedings of the TRB Annual Meeting, Washington, DC, January 2004.

http://www.ltrc.lsu.edu/pdf/TRB2004-000960.pdf

[28] Nasser, M. and Birst, S. (2010) Mesoscopic Evacuation Modeling for Small- to MediumSized Metropolitan Areas. Report to the Advanced Traffic Analysis Center, Upper Great Plains Transportation Institute, North Datoka State University, Fargo. http://www.mountain-plains.org/pubs/pdf/MPC10-222.pdf

[29] Tanaka, K. (2007) Traffic Congestions and Dispersion in Hurricane Evacuation. Physica A: Statistical Mechanics and Its Applications, 376, 617-627. http://dx.doi.org/10.1016/j.physa.2006.10.023

[30] Chen, M. (2005) Traffic Signal Timing for Urban Evacuation. Master's Thesis, Department of Civil Engineering, the University of Maryland, College Park. http://drum.lib.umd.edu/bitstream/1903/2951/1/umi-umd-2744.pdf

[31] Pal, A., Triche, M., Graettinger, A., Rao, K., McFadden, J. and Turner, D. (2005) Enhancements to Emergency Evacuation Procedures. Final Research Report to the University of 
Alabama Transportation Center.

[32] Pal, A. (2008) Emergency Evacuation Modeling Based on Geographical Information System. Thesis Manuscript, Department of Civil Engineering, University of Alabama, Tuscaloosa.

[33] Sisiopiku, V. (2007) Development of Dynamic Traffic Assignment Model to Evaluate Lane Reversal Plans for I-65. UAB School of Engineering. http://main.uab.edu/soeng/Templates/Inner.aspx?pid=98705,2007

[34] University of South Alabama (2003) Mobile Metro Database. www.southalabama.edu/mcob/cber/DB-home.htm

[35] Lindell, M.K., Lu, J.C. and Prater, C.S. (2005) Household Decision Making and Evacuation in Response to Hurricane Lili. Natural Hazards Review, 6, 171-179. http://dx.doi.org/10.1061/(ASCE)1527-6988(2005)6:4(171)

[36] US Army Corps of Engineering (1996) Alabama Hurricane Evacuation Study Technical Data Report: Behavioral Analysis.

[37] Alabama Emergency Management Agency (2011) Hurricane Categories and Hurricane Evacuation Zones. Mobile County Emergency Management Agency.

[38] Mobile County Emergency Management Agency (2014) Hurricane Evacuation Zones. http://www.mcema.net/EvacuationProcedures/HurricaneEvacuationZones.aspx

[39] Florida Department of Transportation (2005) Contraflow Plan for the Florida Intrastate Highway System.

http://www.dot.state.fl.us/trafficoperations/Traf_Incident/pdf/050808_FIHS-Contraflow-M ASTER.pdf

[40] Alabama Department of Transportation (2011) Contraflow Event Log 2004-2010.

Submit or recommend next manuscript to SCIRP and we will provide best service for you:

Accepting pre-submission inquiries through Email, Facebook, LinkedIn, Twitter, etc.

A wide selection of journals (inclusive of 9 subjects, more than 200 journals)

Providing 24-hour high-quality service

User-friendly online submission system

Fair and swift peer-review system

Efficient typesetting and proofreading procedure

Display of the result of downloads and visits, as well as the number of cited articles

Maximum dissemination of your research work

Submit your manuscript at: http://papersubmission.scirp.org/

Or contact jtts@scirp.org 